\title{
Identificação molecular de Mycoplasma mycoides subesp. mycoides tipo SC ioslado do conduto auditivo externo de caprinos clinicamente saudáveis
}

\author{
Molecular indefication of Mycoplasma mycoides subesp. mycoides SC type isolated \\ fro the external auditory meatus of clinically normal goats
}

\author{
Lucieri Olegário Pereira $^{1}$ Maria das Graças Miranda Danelli ${ }^{2}$ \\ Carlos Mazur ${ }^{3}$ Ricardo Galler ${ }^{4}$
}

RESUMO

\begin{abstract}
O trabalho relata a presença de Mycoplasma mycoides subesp. mycoides Tipo SC, biótipo bovino, em caprinos clinicamente saudáveis no Estado do Rio de Janeiro, Brasil, identificado por PCR.
\end{abstract}

Palavras-chave: Mycoplasma mycoides subesp. mycoides Tipo SC, caprino, identificação PCR, Brasil.

\section{ABSTRACT}

The researh shows the presence of Mycoplasma mycoides subsp. mycoides SC Type, bovine biotype, isolated from clinically normal goats in Rio de Janeiro, Brazil, by PCR.

Key words: Mycoplasma mycoides subsp. mycoides SC Type, goats, identification, PCR, Brazil

O Mycoplasma mycoides subesp. mycoides Tipo "Small Colony" (MmmSC) é o agente etiológico da pleuropneumonia contagiosa bovina (PPCB), doença endêmica na África, que reapareceu recentemente na Europa Mediterrânea e na península Ibérica (LAAK, 1992). Além do gado bovino, o MmmSC pode causar doenças em caprinos e ovinos (DAMASSA et al., 1992). Caprinos clinicamente saudáveis podem albergar micoplasmas patogênicos no conduto auditivo externo (RIBEIRO et al., 1995a). Esta condição pode levar a uma infecção aguda, seguida de morte súbita, podendo ainda ser transmitida para outros rebanhos, através de ácaros que coabitam esse ambiente (RIBEIRO et al., 1995b).

O MmmSC pertence a um grupo taxonômico denominado Grupo Mycoplasma Mycoides (GMM), que alberga micoplasmas com características microbiológicas, bioquímicas e sorológicas estreitamente relacionadas. O M. mycoides subesp. mycoides Tipo "Large Colony" (MmmLC) e o M. mycoides subesp. capri (Mmc) também se incluem no GMM (ROSENDAL, 1994). A similaridade existente entre os membros desse grupo dificulta a identificação precisa do MmmSC, através dos testes de diagnóstico

${ }^{1}$ Biólogo, Instituto de Biologia, Universidade Federal Rural de Rio de Janeiro (UFRRJ).

${ }^{2}$ Professor Adjunto, Doutor, Instituto de Veterinária, UFRRJ, BR 465, Km 7, 23851-970, Seropédica, RJ. E-mail: danelli@ufrrj.br Autor para correspondência.

${ }^{3}$ Professor Adjunto, Doutor, Instituto de Veterinária, UFRRJ.

${ }^{4}$ Instituto Oswaldo Cruz, FIOCRUZ/RJ.

Apoio financeiro: Fundação de Amparo à Pesquisa do Estado do Rio de Janeiro. 
tradicionais. Todavia, o emprego de técnicas moleculares, como a reação em cadeia da polimerase (PCR), possibilitou um estudo mais profundo das relações filogenéticas entre os membros do GMM, estabelecendo diferenças genotípicas capazes de distingui-los (NICHOLAS, 1998). A identificação precisa do MmmSC pode trazer informações importantes sobre a presença e a circulação desse patógeno nos rebanhos caprino, ovino e bovino em nosso meio.

O objetivo deste trabalho foi verificar a presença do MmmSC no rebanho caprino de uma propriedade em Nova Friburgo/RJ.

As amostras padrão, pertencentes ao GMM (MmmSC, MmmLC, Mmc), cedidas pelo Dr. E.R. Nascimento/UFF, e 19 amostras de campo classificadas como Mycoplasma spp, isoladas do conduto auditivo externo, obtido de caprinos clinicamente sadios de uma propriedade de Nova Friburgo, no Estado do Rio de Janeiro (BARBOSA et al., 2000), foram cultivadas em meio de Hayflick modificado. O DNA das amostras foi obtido através de extração fenólica (SAMBROOK et al., 1989) e para sua amplificação foram seguidas as recomendações de CHENG et al. (1996). Dois oligonucleotídeos complementares ao gene 72 (P72L e P72R), específicos para MmmSC, foram utilizados, (“Genbank" número de acesso U53210). Para as reações de PCR, foi empregado o termociclador GeneAmp 9600, Perkin Elmer Cetus, programado com 35 ciclos de: 94 ${ }^{\circ} \mathrm{C}, 30$ segundos, $52{ }^{\circ} \mathrm{C}, 30$ segundos, $72{ }^{\circ} \mathrm{C}, 30$ segundos. O resultado das amplificações foi analisado por eletroforese em gel de agarose a $0,8 \%$ em tampão Tris/Borato/EDTA (TBE), corado com brometo de etídeo, sob luz ultravioleta.

Os resultados mostraram que, além da amostra padrão MmmSC, apenas uma amostra de campo foi positiva, gerando um amplicon de cerca de 1,6 kb. A dificuldade de uma classificação precisa dessas amostras foi verificada por BARBOSA et al. (2000), o qual demonstrou que em 56\% das amostras, identificadas como M. mycoides, não foi possível determinar a subespécie. A técnica de PCR foi capaz de identificar, com segurança, a presença do MmmSC, em um lavado do conduto auditivo dos caprinos analisados. A identificação desse patógeno em um número tão pequeno de amostras analisadas pode significar uma elevada circulação do MmmSC em nosso meio, justificando novas pesquisas desse microrganismo em nossos rebanhos.

\section{REFERÊNCIAS BIBLIOGRÁFICAS}

BARBOSA, V.P. et al. Diferenciação de tipos de Mycoplasma mycoides na etiopatogenia da micoplasmose caprina. $\mathbf{R}$ bras Ci Vet, v.7, p. 33-36, 2000.

CHENG, X. et al. Characterization of the gene for an immunodominant $72 \mathrm{KDa}$ lipoprotein of Mycoplasma mycoides subsp. mycoides small colony type. Microbiology, v. 142, p.3515-3524, 1996.

DAMASSA, A.J.; WAKENELL, P.S.; BROOKS, D.L. Mycoplasma of goats and sheeps. J Vet Diagn Invest, v. 4, p.101-113, 1992 .

LAAK, E.A. Contagious bovine pleuropneumonia. A review. Vet Quart, v. 4, p.104-110, 1992.

NICHOLAS, R. The veterinary significance of Mycoplasmas. In: Miles, R.J.; Nicholas, R.A.J. Methods in molecular biology, v. 104: Mycoplasma protocols. Totowa, NJ: Humana, 1998. Cap. 3, p.17-23.

RIBEIRO, V.R. et al. Ocorrência de micoplasmas em caprinos através das técnicas de imunofluorescência direta e inibição de crescimento. R bras Med Vet, v.17, p.26-28, 1995a.

RIBEIRO, V.R. et al. Presença de exemplares de Raillietia caprae coletados do conduto auditivo externo de caprinos. R bras Med Vet, v.17, p.122-124, 1995 b.

ROSENDAL, S. Ovine and caprine mycoplasmas. In: WHITFORD, H.W.; ROSENBUSCH, R.F.; LAURERMAN, L.H. Mycoplasmas in animals: laboratory diagnosis. Ames Iowa State University, 1994. Cap.7, p.84-95.

SAMBROOK, J.; FRITSCH, E.F.; MANIATIS, T. Molecular cloning. A laboratory manual. New York : Cold Spring Harbor Laboratory, 1989. 417p. 